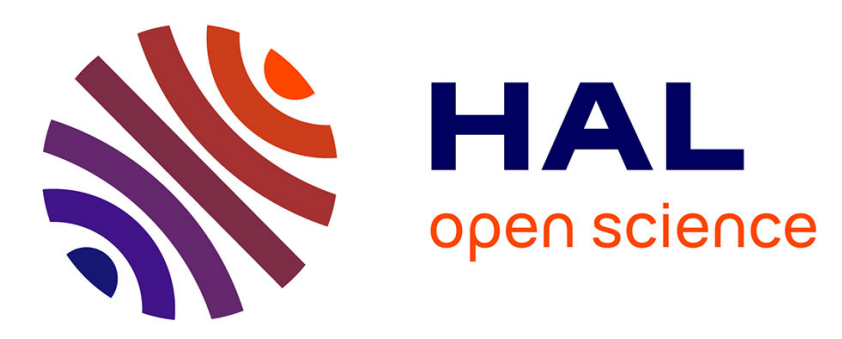

\title{
Study on the cross-correlation of GNSS signals and typical approximations
}

Myriam Foucras, Jérôme Leclère, Cyril Botteron, Olivier Julien, Christophe

Macabiau, P.-A. Farine, Bertrand Ekambi

\section{- To cite this version:}

Myriam Foucras, Jérôme Leclère, Cyril Botteron, Olivier Julien, Christophe Macabiau, et al.. Study on the cross-correlation of GNSS signals and typical approximations. GPS Solutions, 2016, 10.1007/s10291-016-0556-7 . hal-01353985

\section{HAL Id: hal-01353985 \\ https://hal-enac.archives-ouvertes.fr/hal-01353985}

Submitted on 16 Aug 2016

HAL is a multi-disciplinary open access archive for the deposit and dissemination of scientific research documents, whether they are published or not. The documents may come from teaching and research institutions in France or abroad, or from public or private research centers.
L'archive ouverte pluridisciplinaire HAL, est destinée au dépôt et à la diffusion de documents scientifiques de niveau recherche, publiés ou non, émanant des établissements d'enseignement et de recherche français ou étrangers, des laboratoires publics ou privés. 


\title{
Study on the cross-correlation of GNSS signals and typical approximations
}

\author{
Myriam Foucras · Jérôme Leclère · Cyril Botteron • Olivier Julien · Christophe \\ Macabiau • Pierre-André Farine - Bertrand Ekambi
}

\begin{abstract}
In global navigation satellite system (GNSS) receivers, the first signal processing stage is the acquisition, which consists of detecting the received GNSS signals and determining the associated code delay and Doppler frequency by means of correlations with a code and a carrier replicas. These codes, as part of the GNSS signal, were chosen to have very good correlation properties without considering the effect of a potential received Doppler frequency. In the literature, it is often admitted that the maximum GPS L1 C/A code cross-correlation is about $-24 \mathrm{~dB}$. We show that this maximum can be as high as $-19.2 \mathrm{~dB}$ when considering a Doppler frequency in a typical range of $[-5,5] \mathrm{kHz}$. We also show the positive impact of the coherent integration time on the cross-correlation, and that even a satellite with Doppler outside the frequency search space of a receiver impacts the crosscorrelation. In addition, the expression of the correlation is often provided in the continuous time domain while its implementation is typically made in the discrete domain. It is then legitimate to ask the validity of this approximation. Therefore, the purpose of this research is twofold. First, we discuss typical approximations and evaluate their regions of validity. Second, we provide characteristic values such as maximums and quantiles of the auto and cross-correlation of the GPS L1 C/A and Galileo E1 OS codes in presence of Doppler, for frequency ranges up to 50 $\mathrm{kHz}$, and for different integration times.
\end{abstract}

\section{Keywords}

Acquisition - Correlation - Cross ambiguity function · Doppler · Galileo · GPS

\section{Introduction}

The first stage of a global navigation satellite system (GNSS) receiver is acquisition, which consists in determining the Doppler frequency and the code delay of the received GNSS signals (Van Diggelen 2009, pp 127-224). As shown in Fig. 1, this is done by multiplying the received signal with local replicas of the carrier and of the code and integrating the result during a certain time, called coherent integration time and denoted $T_{I}$. The output value then provides the degree of similarity between the replicas and the received signal. Since the receiver does not know a priori the Doppler frequency and the code delay, the different possibilities have to be tested. The output of the acquisition, which is a two-dimensional function of the code delay and Doppler frequency, is called the cross ambiguity function, or CAF (Ipatov 2005, pp. 7-76; Motella et al. 2010). An illustration of a CAF is given in Fig. 1, with a GPS L1 C/A signal where the incoming signal has a Doppler frequency of $2600 \mathrm{~Hz}$ and a code delay of 766 chips. The evaluation of the CAF can be performed sequentially by computing one point after the other, or in parallel using methods based on fast Fourier transforms (FFT) (Akopian 2005; Foucras et al. 2012; Leclère et al. 2013).

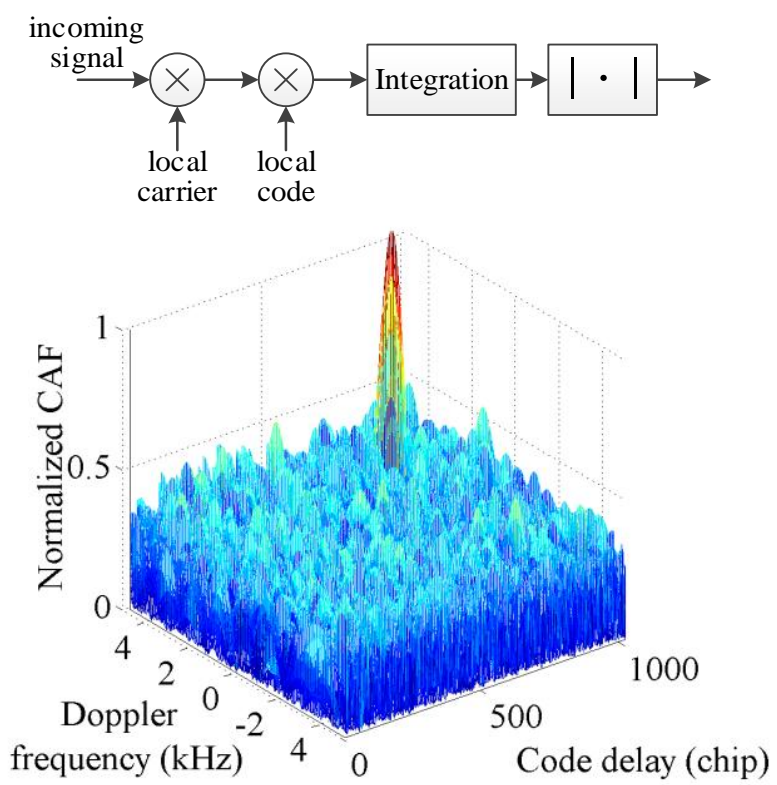

Fig. 1 Principle of the acquisition (top), Illustration of the cross ambiguity function for a GPS L1 C/A signal (bottom) 
Quite often in the literature, approximate models are used for the expression of the CAF. However, the validity of such approximations has not been completely justified. For example, the model provided in Spilker (1996, pp. 57-120), and Holmes (2007, pp. 349-472) considers that the result of the codes correlation is independent from the carrier Doppler frequency, which is actually not the case. Indeed, the real auto and crosscorrelations of the GNSS codes can be affected by a Doppler frequency. For example, Spilker (1996, pp. 57-120) and Kaplan et al. (2005, pp. 113-152) provide the probability that the cross-correlation of C/A codes reaches a certain level, but only for Doppler frequencies multiples of $1 \mathrm{kHz}$. However, as shown later, these frequencies do not necessarily correspond to the worst cases, because they depend on the coherent integration time used. Some papers already discussed the impact of the cross-correlation with a Doppler on the carrier-tonoise ratio or on the tracking discriminator error (Raghavan et al. 1999, Van Dierendonck et al. 2002, Balaei and Akos 2011, Lestarquit and Nouvel 2012, Margaria et al. 2012). Other papers discussed the performance of several families of GNSS codes, looking at the auto and crosscorrelations affected by the carrier Doppler and by the data bit transitions (Soualle et al. 2005, Wallner et al. 2007, Soualle 2009, Qaisar and Dempster 2010). However, the impact of the Doppler frequency is essentially studied only for several frequency candidates or for a small frequency range. Qaisar and Dempster (2007) also presents some results regarding the impact of the sampling frequency and of the Doppler on the code correlation, but only for some specific values.

Therefore, what is missing in the literature is a more exhaustive study regarding the impact of the Doppler frequency for an extensive set of values and the coherent integration time used. Here, we give the auto and cross-correlation results for Doppler frequencies in different frequency ranges corresponding to specific GNSS applications, and the impact of the coherent integration time is also discussed.

The first section presents the signals definitions and the assumptions used. The second section deals with the study of the usual approximations on the CAF. The main objective is to provide the associated region of validity of the approximations. The results regarding the impact of the Doppler frequency in the CAF are presented in the third section, for the GPS L1 C/A and Galileo E1 OS codes. This allows us to compare the auto and cross-correlation properties for each signal. Finally, conclusions are provided.

\section{Signals definitions}

The GPS L1 C/A signal transmitted by a satellite $k$ can be defined as

$s_{k}^{(L 1)}(t)=a_{k} c_{k}(t) d_{k}(t) \sin \left(2 \pi f_{R F} t\right)$

where $t$ is the time, $a_{k}$ is the amplitude of the signal, $c_{k}$ is the pseudo random noise (PRN) code, $d_{k}$ is the data, and $f_{R F}$ is the carrier frequency used by the satellite (Navstar 2014). The GPS L1 C/A codes contain 1023 chips and are generated with a chipping rate of $1.023 \mathrm{MHz}$, the code length is thus $1 \mathrm{~ms}$.

At the receiver antenna, the signal is the sum of $K$ signals coming from $K$ satellites, where each signal is the transmitted signal that has been respectively attenuated, delayed and affected by the Doppler effect. After the antenna, there is the front-end where the signal is amplified, filtered, down-converted to baseband or to an intermediate frequency $f_{I F}$, and sampled at a frequency $f_{s}$. At the output of the front-end, considering a complex sampling, the signal received can be defined as

$$
\begin{gathered}
s_{r}^{(L 1)}\left(n T_{s}\right)=\sum_{k=1}^{K}\left(a_{k} c_{k}\left(n T_{s}-\tau_{k}\right) d_{k}\left(n T_{s}-\tau_{k}\right)\right. \\
\left.e^{j\left(2 \pi\left(f_{I F}+f_{d, k}\right) n T_{S}+\varphi_{k}\right)}\right)+
\end{gathered}
$$

$\eta\left(n T_{s}\right)$

where $T_{s}$ is the sampling period $\left(T_{s}=1 / f_{s}\right), \tau_{k}$ is the delay of the code, $f_{d, k}$ is the Doppler frequency, $\varphi_{k}$ is the carrier phase, and $\eta$ is a white Gaussian noise of zero mean coming from the thermal noise. Note that this model does not take into account some effects, such as the Doppler effect on the code, since it can be neglected regarding the small coherent integration times considered later, or the impact of the oscillator on the sampling frequency (Leclère 2014). Note also that we consider a complex sampling because with a real sampling there would be a term with the sum of frequencies after the mixing with the local carrier that would impact the correlation result 
(Motella et al. 2010). Since we want to investigate specifically the impact of the Doppler frequency and of the coherent integration time, this double frequency term is not wanted. However, the results considering a real or complex sampling would be relatively similar.

In the same way, considering the Galileo E1 OS signal which has a data component and a data free component called pilot, the signal after the frontend can be written as

$s_{r}^{(E 1)}\left(n T_{s}\right)=$

$\sum_{k=1}^{K}\left(a_{k}\left(\begin{array}{c}d_{k}\left(n T_{s}-\tau_{k}\right) c_{D, k}\left(n T_{s}-\tau_{k}\right) p_{D}\left(n T_{s}-\tau_{k}\right) \\ -c_{2}\left(n T_{s}-\tau_{k}\right) c_{P, k}\left(n T_{s}-\tau_{k}\right) p_{P}\left(n T_{s}-\tau_{k}\right)\end{array}\right)\right.$

$$
\left.e^{j\left(2 \pi\left(f_{I F}+f_{d, k}\right) n T_{s}+\varphi_{k}\right)}\right)+\eta\left(n T_{s}\right)
$$

where $c_{2}$ is the secondary code on the pilot component, and $p_{D}$ and $p_{P}$ denote the data and pilot subcarriers due to $\mathrm{CBOC}$ modulation as defined in European Union (2015). The Galileo E1 OS codes contain 4092 chips and are generated with a chipping rate of $1.023 \mathrm{MHz}$, the codes length is thus $4 \mathrm{~ms}$.

In this study, it is assumed that the navigation data $d$ and secondary code $c_{2}$ are constant during the integration. See Wallner et al. (2007) and Soualle (2009) for some results considering a bit sign transition during the integration. Also, the filtering and quantization performed by the frontend are not taken into account. See Curran et al. (2010) for more details about that topic. Finally, the noise term is not considered since the focus of this research is on the correlation properties.

\section{Study of usual approximations}

In this section, we perform a study on two typical approximations, the first uses a continuous time domain model although actual processing is performed in discrete time domain, and the second models the CAF assuming that the code and Doppler are independent. For simplicity, we develop the results for the GPS L1 C/A signal, i.e. $s_{r}=s_{r}^{(L 1)}$, since they can be easily extended to the Galileo E1 OS signal and other GNSS signals.

\section{Approximation continuous/discrete}

In the literature, e.g. Kaplan et al. (2005, pp. 113152) and Holmes (2007, pp. 349-472), the output of the CAF is often modeled by the following continuous time version:

$$
\begin{aligned}
& S_{k, l}^{c}\left(\hat{\tau}, \hat{f}_{d}\right) \\
& =\left|\int_{0}^{T_{I}} s_{r}(t) c_{l}(t-\hat{\tau}) e^{-j 2 \pi \hat{f}_{d} t} d t\right| \\
& =\mid a_{k} \int_{0}^{T_{I}} c_{k}\left(t-\tau_{k}\right) c_{l}(t \\
& \quad-\hat{\tau}) e^{j\left(2 \pi\left(f_{d, k}-\hat{f}_{d}\right) t+\varphi_{k}\right)} d t \mid
\end{aligned}
$$

where the superscript $c$ stands for continuous, $\mathrm{k}$ denotes the L1 C/A code number of the code received, l denotes the $\mathrm{L} 1 \mathrm{C} / \mathrm{A}$ code number of the code replica, $\hat{\tau}$ is the local estimate of the code delay, and $\hat{f}_{d}$ is the local estimate of the carrier frequency. This expression is an approximation of what is really performed in a GNSS receiver since the signals are actually discrete. Thus, the actual output of the CAF is

$$
\begin{aligned}
& S_{k, l}^{d}\left(\hat{\tau}, \hat{f}_{d}\right) \\
& =\left|\sum_{n=0}^{N-1} s_{r}\left(n T_{s}\right) c_{l}\left(n T_{s}-\hat{\tau}\right) e^{-j 2 \pi \hat{f}_{d} n T_{s}}\right| \\
& =\mid a_{k} \sum_{n=0}^{N-1} c_{k}\left(n T_{s}-\tau_{k}\right) c_{l}\left(n T_{s}\right. \\
& \quad-\hat{\tau}) e^{j\left(2 \pi\left(f_{d, k}-\hat{f}_{d}\right) n T_{s}+\varphi_{k}\right)} \mid
\end{aligned}
$$

where the superscript $d$ stands for discrete, and $N$ is the number of samples during the coherent integration time, i.e. $N=T_{I} f_{s}$. Remember that (5) is still an approximation, since it does not take into account the filtering of the front-end and the other factors mentioned in the previous section.

Therefore, the question is "are the results obtained with (4) close to those obtained with (5) ?", which is intuitively believed to be the case. To check this, both equations have been evaluated for all the GPS L1 C/A codes, with a step of $10 \mathrm{~Hz}$ for $\hat{f}_{d}$ over a range of $50 \mathrm{kHz}$ and a step of 1 chip for $\hat{\tau}$, and considering one sample per chip. The details of how to compute exactly the integral of (4) are given in the Appendix.

Fig. 2 shows the difference between $S_{k, l}^{d}\left(\hat{\tau}, \hat{f}_{d}\right)$ and $S_{k, l}^{c}\left(\hat{\tau}, \hat{f}_{d}\right)$ as function of the code delay and Doppler frequency, and shows the distribution of this difference. It can be seen that the higher the Doppler frequency, the higher is the difference 
between the two results, but this difference is clearly negligible since the maximum difference is $0.0342 \mathrm{~dB}$ for a Doppler of $50 \mathrm{kHz}$. Therefore, we can conclude that using (4) as approximation of (5) is a valid hypothesis.
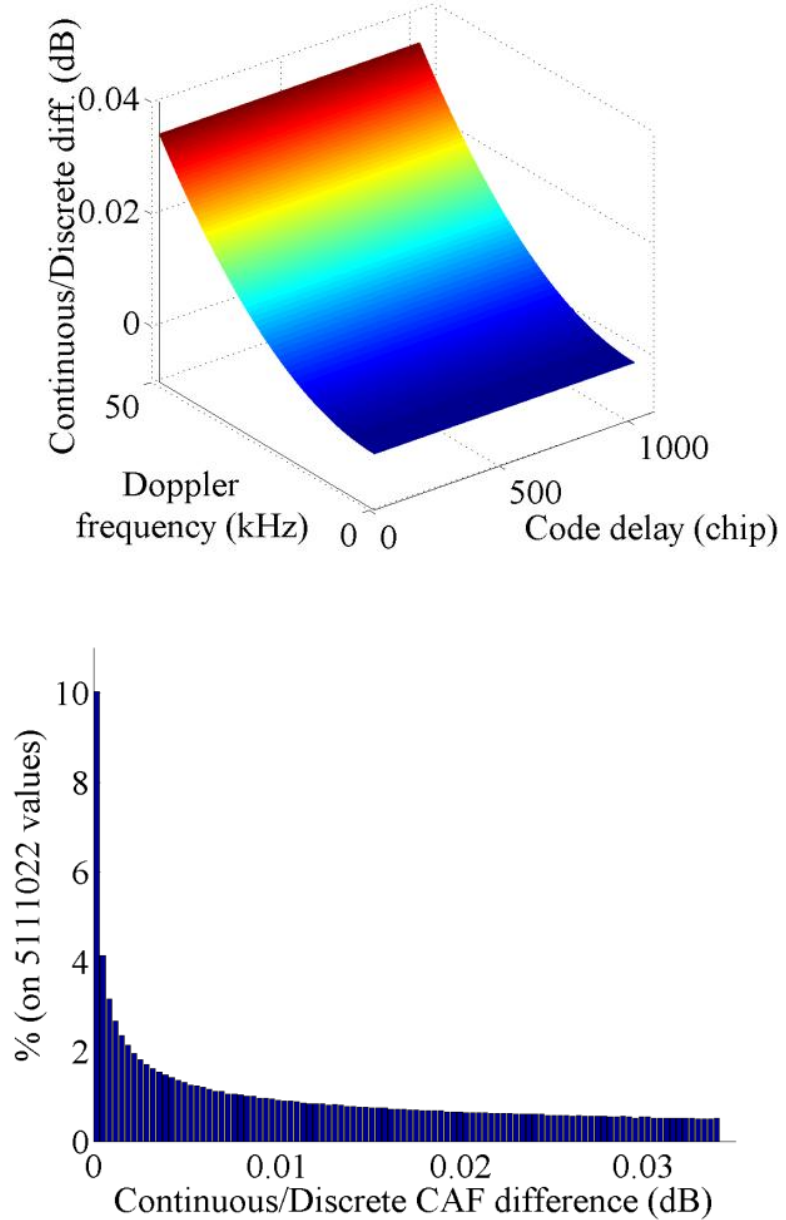

Fig. 2 Difference between the CAF in the discrete and continuous cases, i.e. $S_{k, l}^{d}\left(\hat{\tau}, \hat{f}_{d}\right)-S_{k, l}^{c}\left(\hat{\tau}, \hat{f}_{d}\right)$, assuming receiving and generating L1 C/A code 1

Approximation on cross ambiguity function In the literature, e.g. Holmes (2007, pp. 349-472), the output of the CAF is often approximated as

$\overline{S_{k, l}^{c}}\left(\hat{\tau}, \widehat{f_{d}}\right)=\left|R_{k, l}\left(\Delta_{\tau}\right) \operatorname{sinc}\left(\pi \Delta_{f} T_{I}\right)\right|$

where $\Delta_{\tau}=\tau_{k}-\hat{\tau}$ is the difference of code delays, $\Delta_{f}=f_{d, k}-\hat{f}_{d}$ is the difference of carrier frequencies, and $R_{k, l}$ is the cross-correlation between the codes $k$ and $l$, defined as

$R_{k, l}\left(\Delta_{\tau}\right)=\int_{0}^{T_{I}} c_{k}(t) c_{l}\left(t-\Delta_{\tau}\right) d t$

If $k=l, R_{k, k}$ is the autocorrelation of the code $k$. The approximation given by (6) is the result of the following operation:

$\overline{S_{k, l}^{c}}\left(\hat{\tau}, \hat{f}_{d}\right)$

$$
\begin{aligned}
=\mid \int_{0}^{T_{I}} c_{k}\left(t-\tau_{k}\right) c_{l}(t & \\
& -\hat{\tau}) d t \int_{0}^{T_{I}} e^{j\left(2 \pi\left(f_{d, k}-\hat{f}_{d}\right) t+\varphi_{k}\right)} d t \mid
\end{aligned}
$$

which is clearly not equal to (4). In Holmes (2007, pp. 349-472), it is mentioned that $R_{k, l}$ in (6) has been factored out of the integral as an approximation assuming that $\Delta_{f}$ is small compared to the chip rate.
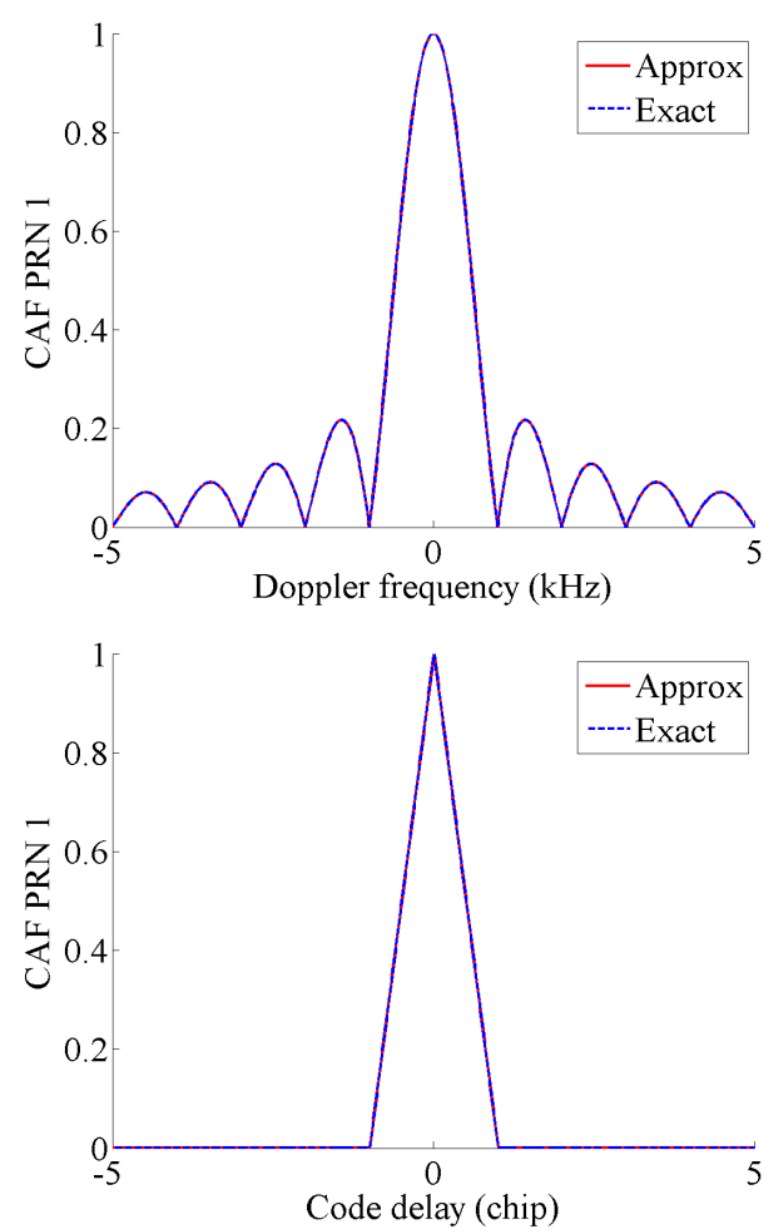

Fig. 3 Comparison of the CAF of L1 C/A code 1 computed using (4) and (6) when $\Delta_{\tau}=0$ chip (top), and $\Delta_{f}=0 \mathrm{~Hz}$ (bottom)

Therefore, the question is "when this approximation is valid, i.e. when the results obtained with (6) are equal or very close to those obtained with (4) ?". First, it can be easily checked that if $\Delta_{\tau}=0$, i.e. $\hat{\tau}=\tau_{k}$, or if $\Delta_{f}=0$, i.e. $\hat{f}_{d}=f_{d, k}$, equation (6) is identical to (4), i.e.

$\overline{S_{k, l}^{c}}\left(\tau_{k}, \hat{f}_{d}\right)=S_{k, l}^{c}\left(\tau_{k}, \hat{f}_{d}\right)$ 
$\overline{S_{k, l}^{c}}\left(\hat{\tau}, f_{d, k}\right)=S_{k, l}^{c}\left(\hat{\tau}, f_{d, k}\right)$

This is illustrated by Fig. 3with $T_{I}=1 \mathrm{~ms}$. As a note, the CAF is symmetric with respect to $\Delta_{f}=0$, but not to $\Delta_{\tau}$. Note that the model used does not consider any filtering; in practice the bandwidth is limited and the correlation peak is rounded.

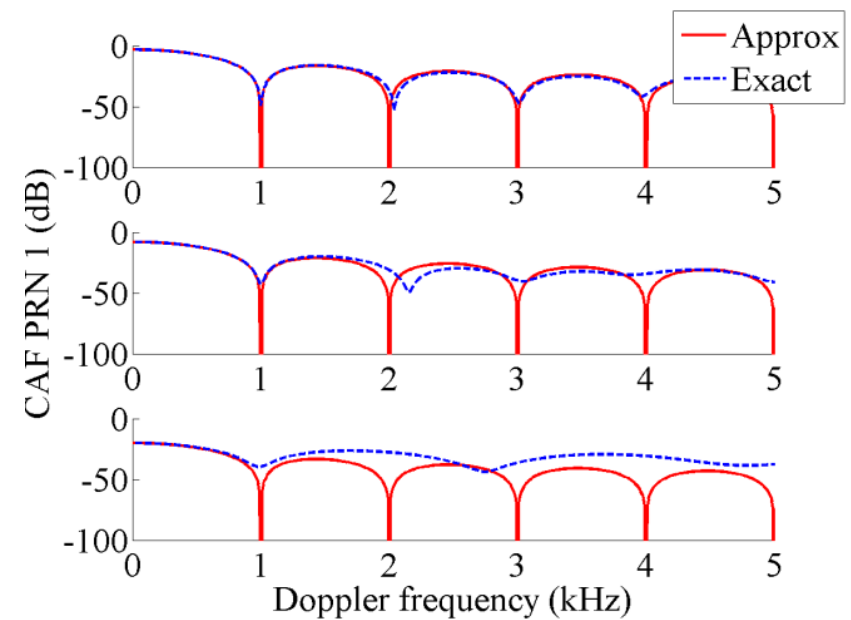

Fig. 4 Comparison of the CAF of L1 C/A code 1 computed using (4) and (6) when $\left|\Delta_{\tau}\right|<1$ chip. $\Delta_{\tau}=0.3$ chip (top), $\Delta_{\tau}=0.6$ chip (middle), $\Delta_{\tau}=0.9$ chip (bottom)

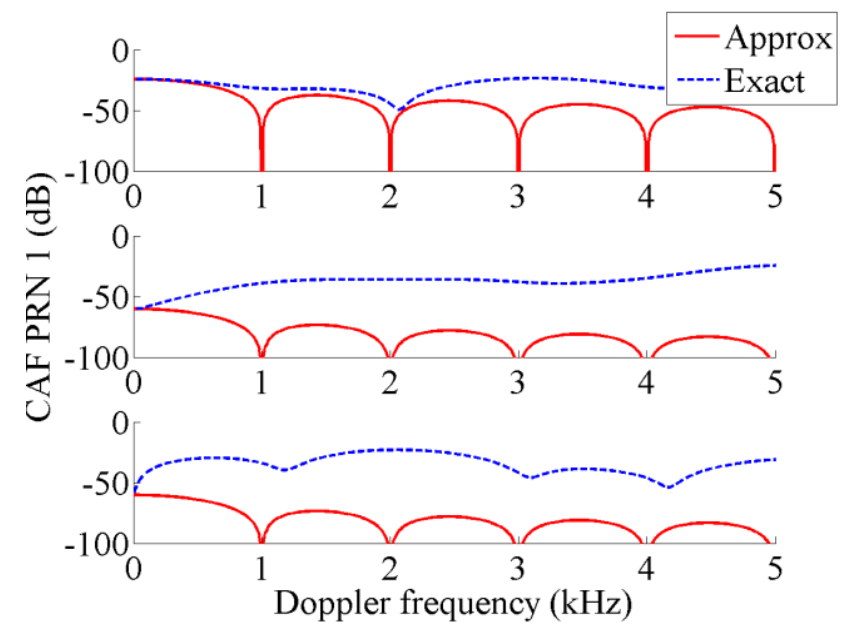

Fig. 5 Comparison of the CAF of L1 C/A code 1 computed using (4) and (6) when $\left|\Delta_{\tau}\right|>1$ chip. $\Delta_{\tau}=200$ chips (top), $\Delta_{\tau}=400$ chips (middle), $\Delta_{\tau}=600$ chips (bottom)

Then, as shown in Fig. 4, if $\left|\Delta_{\tau}\right|<1$ chip, the approximation is very close to the exact value when $\Delta_{f}<1 \mathrm{kHz}$, i.e. for the main lobe of the sinc. Outside the main lobe, the approximation differs from the exact value. The higher $\left|\Delta_{\tau}\right|$, the higher is the difference. However, when $\left|\Delta_{\tau}\right| \geq$
1 chip, there are two cases as shown in Fig. 5 and Fig. 6. If the code autocorrelation without Doppler is very low, i.e. near $-60 \mathrm{~dB}$, a small error in the Doppler such as dozens of hertz will imply few $\mathrm{dB}$ of difference rapidly. However, if the code autocorrelation without Doppler is not too low, i.e. near $-24 \mathrm{~dB}$, the difference will be seen for a higher error in the Doppler, from hundreds of hertz, i.e. for frequencies within the main lobe. Finally, regarding the cross-correlation between two different codes, shown in Fig. 7, this case is similar to the case of the autocorrelation with $\left|\Delta_{\tau}\right|>1$ chip shown in Fig. 5 .

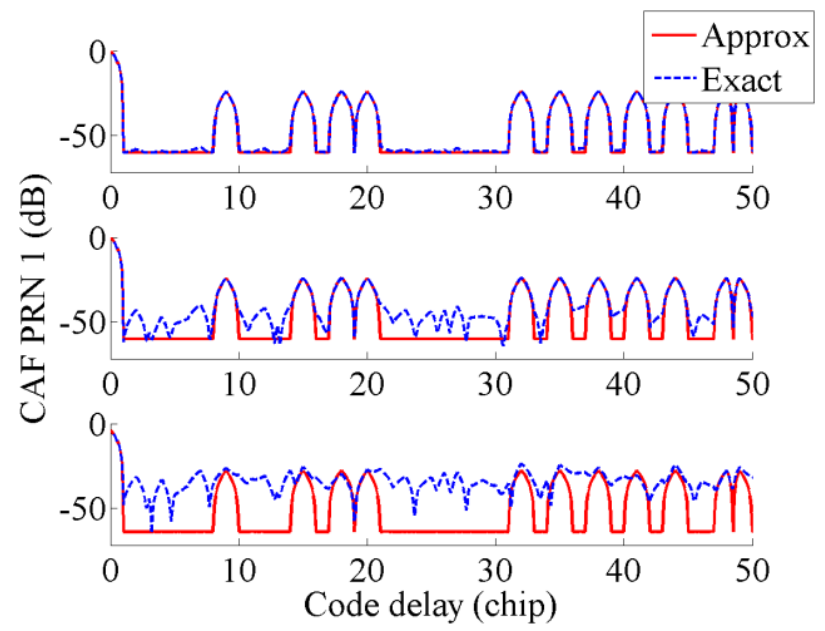

Fig. 6 Comparison of the CAF of L1 C/A code 1 computed using (4) and (6) when $\left|\Delta_{f}\right|>0 \mathrm{~Hz}$. $\Delta_{f}=10 \mathrm{~Hz} \quad$ (top), $\Delta_{f}=100 \mathrm{~Hz} \quad$ (middle), $\Delta_{f}=500 \mathrm{~Hz}$ (bottom)

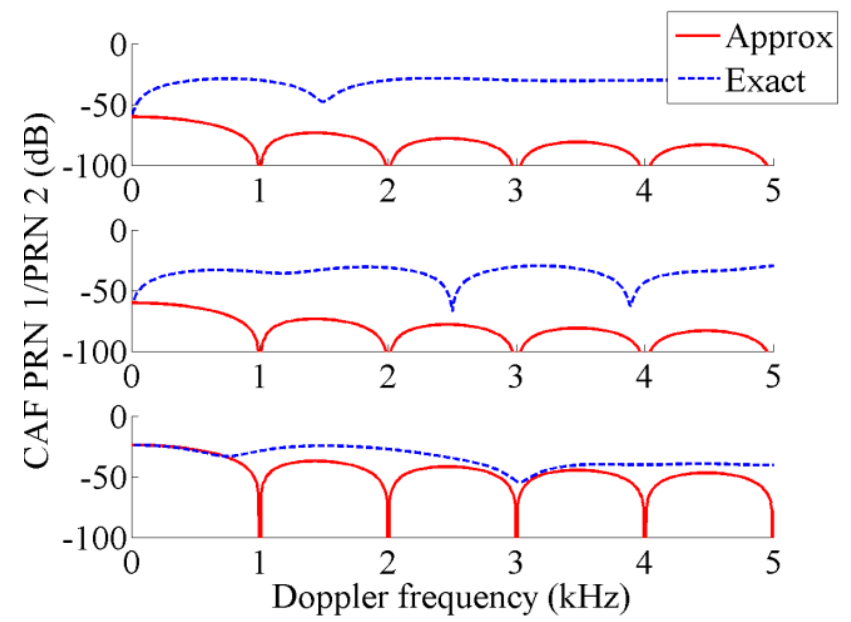

Fig. 7 Comparison of the CAF of L1 C/A code 1/ L1 C/A code 2 computed using (4) and (6). $\Delta_{\tau}=400$ chips (top), $\Delta_{\tau}=600$ chips (middle), $\Delta_{\tau}=474$ chips (bottom) 
In order to have a global representation of the previous discussions, Fig. 8 shows in blue the areas where the difference between the exact computation and the approximation is lower than $1 \mathrm{~dB}$. In conclusion, it has been verified that the continuous-time expression of the CAF is a very good approximation of the discrete-time one. Furthermore, it has been observed that the CAF approximation that considers the code and Doppler independently given by (6) is:

- Exact for a right estimation of the code delay or of the Doppler frequency (Fig. 3).

- Quite exact for a code delay less than 1 chip and a Doppler frequency less than $1 \mathrm{kHz}$, the inverse of the code period (Fig. 4), corresponding to the main peak.

- Quite exact for a code delay leading to a not too low correlation value such as $-24 \mathrm{~dB}$ and a Doppler frequency less than about $200 \mathrm{~Hz}$ (Fig. 5 top and Fig. 6).

- Not valid for a code delay leading to not too low correlation value such as $-24 \mathrm{~dB}$ and a Doppler frequency higher than about $200 \mathrm{~Hz}$ (Fig. 5 top and Fig. 6)

- Not valid for a code delay leading to a very low correlation value such as $-60 \mathrm{~dB}$ as soon as there is a very small Doppler frequency (Fig. 5 middle and bottom and Fig. 6).

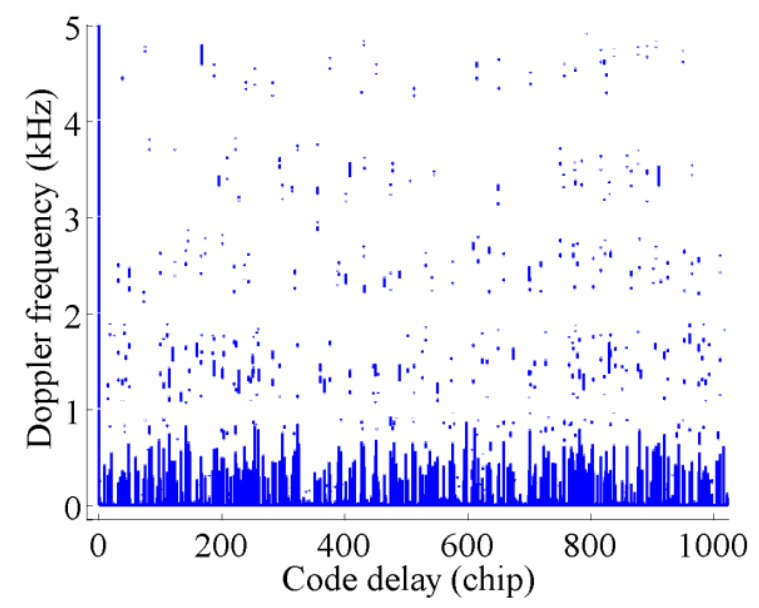

Fig. 8 Difference between exact computation and approximation of the CAF for the L1 C/A code 1 . Blue dots correspond to a not null difference smaller than $1 \mathrm{~dB}$.

\section{Evaluation of the correlation properties}

In the previous section, it has been shown that the usual approximation that considers separately the code correlation and the sinc function is not representative of reality. Therefore, it is interesting to evaluate the level of the CAF for various Doppler frequencies. In this section, we provide statistics related to the values of the CAF for the auto and cross-correlation for the GPS L1 C/A and Galileo E1 OS codes; in particular, we give maximum values, distribution, i.e. probability of occurrence, and cumulative distribution through some quantiles.

\section{Simulation scheme}

The presented results come from exhaustive simulation runs for all the codes or couples of codes, for all code delays multiple of 1 chip, and for Doppler frequencies within different ranges using a step of $10 \mathrm{~Hz}$. In order to speed up the computation time, the CAFs are computed following

$S_{k, l}^{d}\left(\hat{f}_{d}\right)=$

$\frac{1}{N T_{s}}\left|\operatorname{IFFT}\left(\operatorname{FFT}\left(c_{k} e^{-j 2 \pi \hat{f}_{d} n T_{s}}\right) \mathrm{FFT}^{*}\left(c_{l}\right)\right)\right|$

which is similar to (5) but provides the result for all code delays $\hat{\tau}$ with a step of one sample Borre et al. (2007 pp. 75-86). The corresponding simulation scheme is presented in Fig. 9.

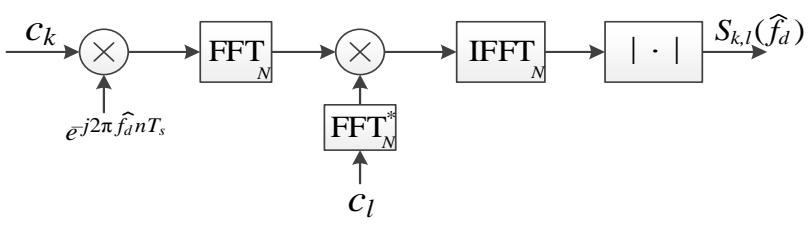

Fig. 9 Simulation scheme

Autocorrelation

In this section, we present statistics related to the values of the CAF for the autocorrelation for the GPS L1 C/A and Galileo E1 OS codes.

\section{GPS L1 C/A signal}

Without any Doppler and except for the correct alignment, the autocorrelation of a C/A code can take only three possible values: 1/1023, 63/1023 and $-65 / 1023$, which gives in log scale $-60.20 \mathrm{~dB}$, $-24.21 \mathrm{~dB}$ and $-23.94 \mathrm{~dB}$, respectively. Now, if we include a Doppler frequency, the correlation characteristics change drastically and the maximum autocorrelation value can be up to 
$-19.18 \mathrm{~dB}$, as shown in Fig. 10. In this figure, it can be seen that the maxima are different according to the L1 C/A code, and that they are not related to a specific frequency. Note that by Doppler frequency we mean Doppler frequency residual, i.e. the difference between the received and the local carrier frequencies. It is important to stress that it is the absolute value of the difference between these two frequencies that matters, not the frequencies themselves, as shown in the Appendix. Therefore, receiving a Doppler frequency of $1000 \mathrm{~Hz}$ and generating a local frequency of $2500 \mathrm{~Hz}$ (difference of $1500 \mathrm{~Hz}$ ) gives exactly the same correlation result as with frequencies of 2500 and $1000 \mathrm{~Hz}$ respectively or with frequencies of 1500 and $3000 \mathrm{~Hz}$ respectively. This is why Fig. 10 shows only the positive frequencies on the $\mathrm{X}$-axis.

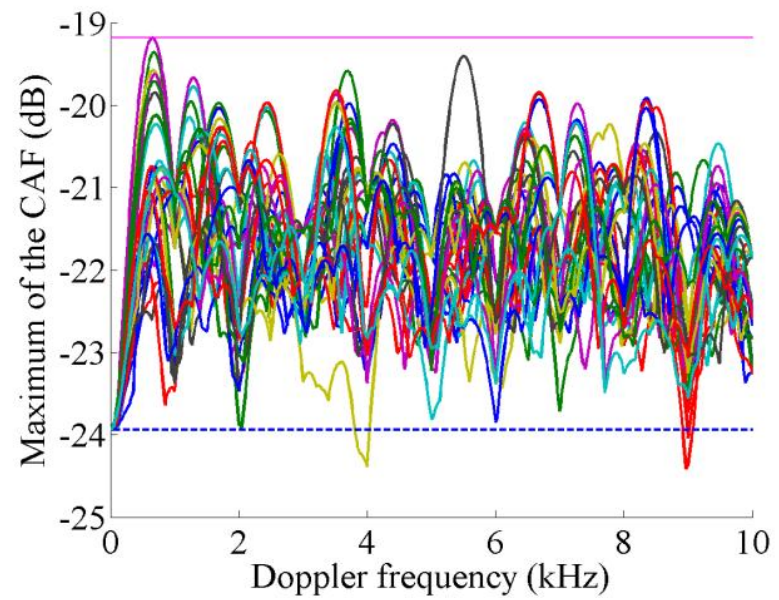

Fig. 10 Maximum of the CAF excluding the correct alignment as a function of the Doppler frequency, for an integration time of $1 \mathrm{~ms}$, i.e. one code period. Each color represents a different L1 C/A code. The horizontal blue dotted line represents the CAF for a $0 \mathrm{~Hz}$ Doppler, i.e. $-23.94 \mathrm{~dB}$. The horizontal magenta line represents the maximum CAF for a not null Doppler, i.e. $19.18 \mathrm{~dB}$.

For a more complete evaluation, a statistical description is provided with different characteristic quantiles. For this, in addition to the $0 \mathrm{~Hz}$ Doppler case, four frequency bands corresponding to different GNSS users are defined:

- $\quad[-500 ; 500] \mathrm{Hz}$, which corresponds to a typical frequency search space for an assisted receiver (Van Diggelen 2009, pp. 31-60),

- $[-5 ; 5] \mathrm{kHz}$, for a terrestrial receiver (Tsui, 2005 pp. 30-50),

- $[-10 ; 10] \mathrm{kHz}$, for a receiver on a plane (Tsui 2005 pp. 30-50),

- $\quad[-50 ; 50] \mathrm{kHz}$, for a spaceborne receiver in low earth orbit (Dion et al. 2010).

Fig. 11 provides the statistical description of the CAF of GPS L1 C/A codes when considering these different Doppler frequency ranges. The black bar represents the $0 \mathrm{~Hz}$ Doppler case, and the horizontal blue dotted line represents the $0 \mathrm{~Hz}$ Doppler worst case, i.e. $-23.94 \mathrm{~dB}$. The interpretation of Fig. 11 is that for a Doppler frequency in the band $[-5 ; 5] \mathrm{kHz}\left(3^{\text {rd }}\right.$ bar in the histogram), $90 \%$ of the CAF values are below $26.18 \mathrm{~dB}$, i.e. there is only one point of the CAF over 10 that has a higher value. In the same way, still for the band $[-5 ; 5] \mathrm{kHz}$, looking at the quantile $99.9 \%$ only one point over 1000 has a value higher than $-21.5 \mathrm{~dB}$; and looking at the quantile $100 \%$ the maximum $\mathrm{CAF}$ value is $-19.18 \mathrm{~dB}$. As it can be observed, for all the frequency bands, there is at least $1 \%$ of the points (99\%) of the CAF that are above the $0 \mathrm{~Hz}$ Doppler worst case of $-23.94 \mathrm{~dB}$.

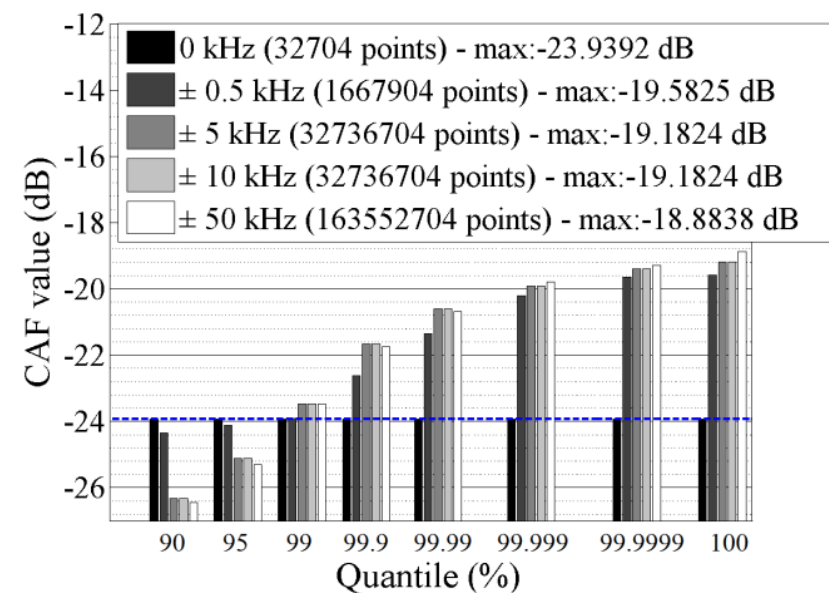

Fig. 11 Level of CAF values excluding the correct alignment according to the selected quantiles and for different frequency bands, considering the 32 $\mathrm{L} 1 \mathrm{C} / \mathrm{A}$ codes and an integration time of $1 \mathrm{~ms}$

The same study has been done considering longer coherent integration times. In Fig. 12, we report the maximum of the CAF in the band $[-5$; 5] $\mathrm{kHz}$ for different coherent integration times (1, 2, 4, 10 and $20 \mathrm{~ms}$ ). It can be seen that with longer 
integration times, the values on multiples of $1 \mathrm{kHz}$ are the same while the values on not multiples of $1 \mathrm{kHz}$ decrease. Therefore, when the coherent integration time is longer than the code period, the CAF maximums are on multiples of $1 \mathrm{kHz}$.
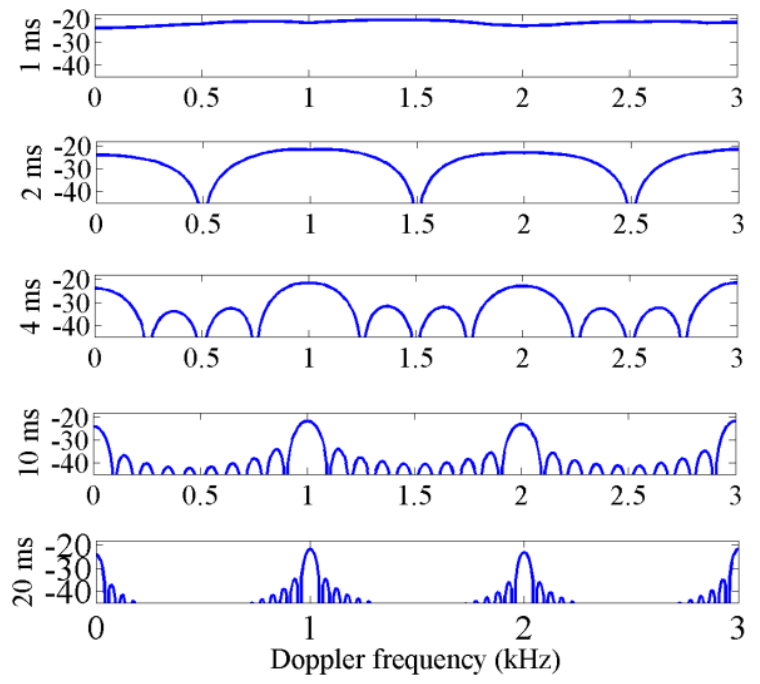

Fig. 12 Maximum of the CAF excluding the correct alignment of the GPS L1 C/A code 1 as a function of the Doppler frequency, for integration times of 1, 2, 4, 10 and $20 \mathrm{~ms}$, respectively

This can be intuitively explained looking at the spectrum of L1 C/A codes. Since the C/A codes are periodic with a period of $1 \mathrm{~ms}$, their spectrum is discrete and the spectral lines are spaced by $1 \mathrm{kHz}$ (Spilker 1996, pp. 57-120), as illustrated in Fig. 13 (left) which zooms around $0 \mathrm{~Hz}$, and where the height of each line depends on the code. The product of two L1 C/A codes is another L1 C/A code of the same period (Spilker 1996, pp. 57-120) therefore its spectrum is similar. A C/A code with a carrier Doppler has a spectrum almost similar to the one of a C/A code except that it is shifted, as illustrated Fig. 13 (right). Therefore, the product of a received $\mathrm{C} / \mathrm{A}$ code with a carrier Doppler by a local C/A code will have a spectrum as shown in Fig. 13 (bottom). Such signal is then integrated; the transfer function of the integration is a sinc function as illustrated in Fig. 13 (bottom). Therefore, considering first an integration time of $1 \mathrm{~ms}$, if the incoming signal has no Doppler, we have the spectrum shown in Fig. 14 (top left), where it can be seen that only the line at $0 \mathrm{~Hz}$ is kept after the integration. If the incoming signal has a Doppler of $500 \mathrm{~Hz}$, we have the spectrum shown in Fig. 14 (middle left), and all the spectrum lines will be attenuated but conserved. If the incoming signal has a Doppler of $1000 \mathrm{~Hz}$, we have the spectrum shown inFig. 14 (bottom left), and again only the line at $0 \mathrm{~Hz}$ is kept after the integration.

Now, if we consider an integration time of $4 \mathrm{~ms}$, the width of the sinc in the transfer function will be four times smaller. If the incoming signal has a Doppler that is a multiple of $1 \mathrm{kHz}$, see Fig. 14 (top and bottom right), only the line at $0 \mathrm{~Hz}$ is kept after the integration, which gives exactly the same result as with an integration of $1 \mathrm{~ms}$. This explains why the correlation value is the same for Doppler that are multiple of $1 \mathrm{kHz}$ whatever the integration time is. But now, with a Doppler that is a multiple of $250 \mathrm{~Hz}=\frac{1}{4 \mathrm{~ms}}$, all the spectrum lines will be cancelled as shown in Fig. 14 (middle right). This explains the nulls that appear in Fig. 12 when the integration time is increased. Note that these nulls can also be found analytically using (17), given in the Appendix. Finally, for other Doppler shifts all the spectrum lines will be attenuated and conserved, but the attenuation is much more compared to an integration time of $1 \mathrm{~ms}$, which explains the lower CAF values.

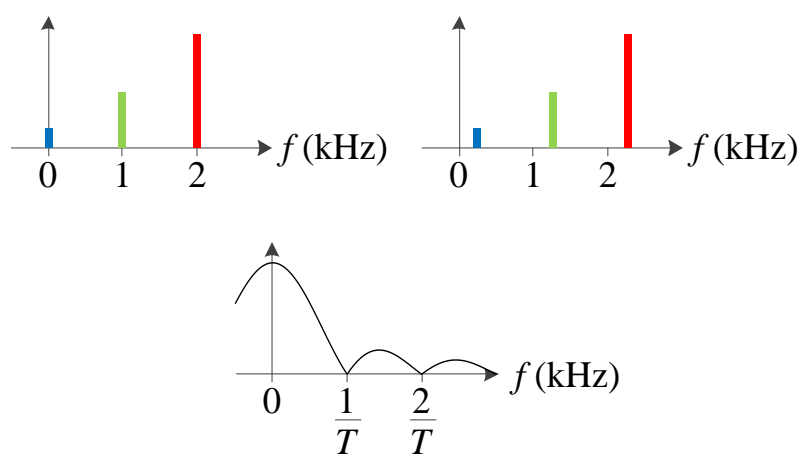

Fig. 13 Spectrum of a C/A code without carrier Doppler (left), spectrum of a C/A code with a carrier Doppler (right), transfer function of an integration of duration $T$ ms (bottom) 


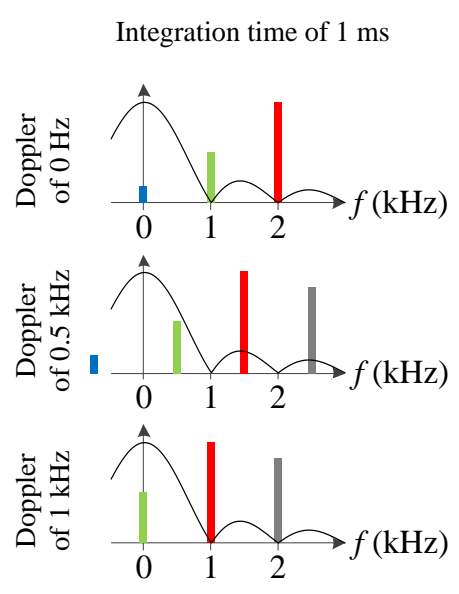

Integration time of $4 \mathrm{~ms}$

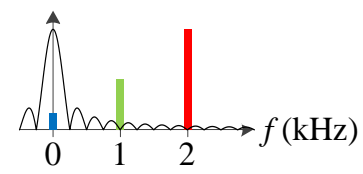

Fig. 14 Spectrum of a C/A code shifted by a Doppler frequency of $0 \mathrm{~Hz}$ (top), $500 \mathrm{~Hz}$ (middle) and $1 \mathrm{kHz}$ (bottom), and transfer function using $1 \mathrm{~ms}$ of integration time (left) and using $4 \mathrm{~ms}$ of integration time (right)

These observations are completed with the distributions of the CAF presented in Fig. 15. For example, with an integration time of $1 \mathrm{~ms}, 90 \%$ of the values are below $-26.35 \mathrm{~dB}$, as already shown in Fig. 11, whereas with an integration time of $20 \mathrm{~ms}, 90 \%$ of the values are below $-44.56 \mathrm{~dB}$ (more than $18 \mathrm{~dB}$ ). In conclusion, the use of a coherent integration time longer than the code period is much better in terms of cross-correlation protection.

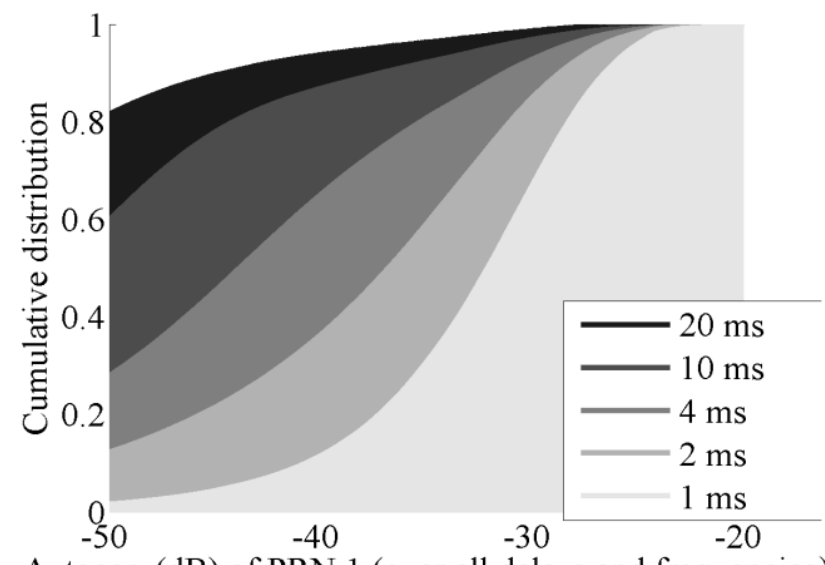

Autocor. (dB) of PRN 1 (over all delays and frequencies)

Fig. 15 Cumulative distribution of the CAF excluding the correct alignment of L1 C/A code 1, for different coherent integration times, and a search space of $[-10 ; 10] \mathrm{kHz}$
The same study is now presented for the Galileo E1 OS signal. In this case, only the first 3 Doppler frequency ranges are considered. Indeed, because of the higher number of codes and number of code delays, to be exhaustive the quantiles should be computed on several tens of billions of points for a Doppler range of $[-50 ; 50] \mathrm{kHz}$, which is not possible due to Matlab memory limits (using Matlab R2014a version).

Unlike GPS L1 C/A codes, for Galileo E1 OS codes, when not considering Doppler frequency, the number of possible autocorrelation or crosscorrelation values is not limited to 4 values. However, thanks to their longer lengths, $4 \mathrm{~ms}$ instead of $1 \mathrm{~ms}$, the maximum autocorrelation value excluding the correct alignment of Galileo E1 codes is $-25.39 \mathrm{~dB}$ without Doppler, which is lower than the maximum of $-23.94 \mathrm{~dB}$ with the GPS L1 C/A codes. Nonetheless, with a Doppler up to $10 \mathrm{kHz}$, the maximum can be up to $-23.45 \mathrm{~dB}$.

Fig. 16 shows the values for some probabilities of occurrence for the different frequency bands and for the data and pilot codes. It can be observed that the autocorrelation properties of the Galileo E1 OS codes assigned to the data component are equivalent to those of the codes assigned to the pilot component in terms of distribution, and that the autocorrelation without any Doppler has indeed a multitude of different levels. It can also be observed that there is a global improvement of 2 to $8 \mathrm{~dB}$ compared to the GPS L1 codes, thanks to a code length that is four times longer.

\section{Galileo E1 OS}



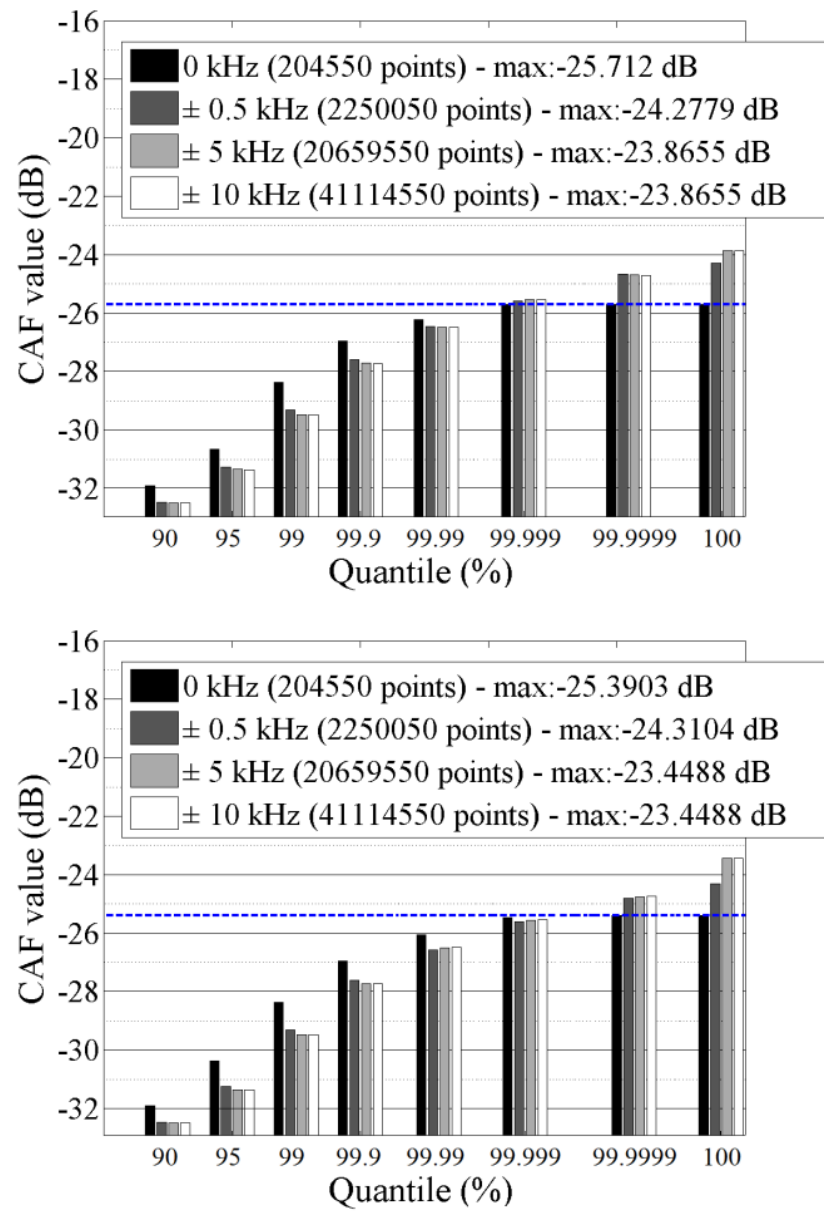

Fig. 16 Level of CAF values excluding the correct alignment according to the selected quantiles and for different frequency bands, considering the 100 Galileo E1 OS codes and an integration time of 4 ms. Galileo E1 OS data codes (top), Galileo E1 OS pilot codes (bottom)

Obviously, in the case of the Galileo E1 OS signals, and more generally for the modernized GNSS signals, bit sign transitions can occur at each spreading code period whereas for GPS L1 C/A signals, 19 spreading code periods are free of bit transitions (Foucras 2015). In this study, it is assumed that there is no bit sign transition.

The maximum of the CAF is shown in Fig. 17 for the band $[-5 ; 5] \mathrm{kHz}$ and different integration times. It can be seen that the values on the multiples of $250 \mathrm{~Hz}$ are the same whatever is the integration time, which was expected given the $4 \mathrm{~ms}$ period of the primary codes.
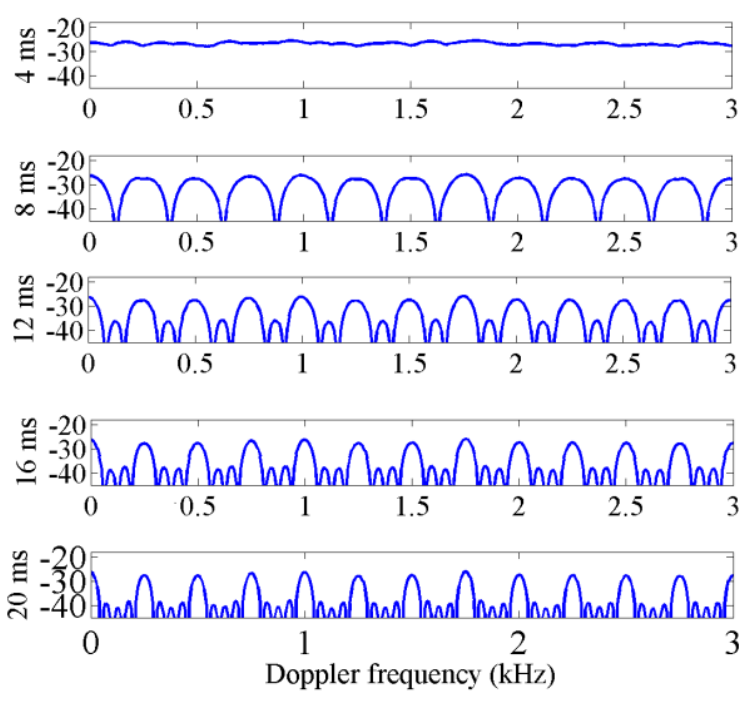

Fig. 17 Maximum of the CAF excluding the correct alignment of the Galileo E1 OS data code 1 as function of the Doppler frequency, for integration times of $4,8,12,16$ and $20 \mathrm{~ms}$, respectively

Concluding this section on the autocorrelation, we present Table 1, which allows us to compare the autocorrelation values for the presented quantiles. When comparing the GPS L1 C/A and Galileo E1 OS code isolations, it can be observed that Galileo E1 OS codes have better correlation performance for an integration time equal to the spreading code period, with an improvement between 4 and $6 \mathrm{~dB}$. Even if we compare both code families with the same integration time of $4 \mathrm{~ms}$, the maximum is at least $2 \mathrm{~dB}$ lower for Galileo E1 OS codes. However, for a coherent integration time of $20 \mathrm{~ms}$, which corresponds to 20 L1 C/A code periods or 5 Galileo E1 OS code periods, the lowest quantiles (90\% and $95 \%$ ) are lower for GPS L1 C/A. But things are different for the other quantiles ( $99 \%$ and above) for which Galileo E1 codes perform better by at least $3 \mathrm{~dB}$. This can be understood looking at Fig. 12 and Fig. 17, where we can see that there are more high lobes with the Galileo E1 OS signal, but the local maxima are still below the local maxima of the GPS L1 C/A signal. Note that only the first 6 Galileo E1 OS data codes have been used due to memory constraints. It is important to note that these results do not take into account the square sub-carrier modulation of BOC modulation. 
Table 1 Levels of CAF values in $\mathrm{dB}$ according to the distribution considering $[-10 ; 10] \mathrm{kHz}$ as range for the Doppler frequency. For the integration time of $20 \mathrm{~ms}$, only the first 6 Galileo E1 OS data codes have been used due to memory constraints.

\begin{tabular}{|c|c|c|c|c|c|}
\hline$T_{I}(\mathrm{~ms})$ & - & $\nabla$ & $\nabla$ & กิ & तิ \\
\hline Signal & 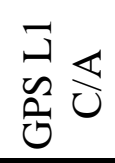 & 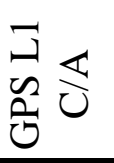 & 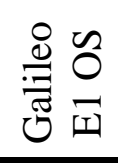 & $\underset{\tilde{0}}{\overrightarrow{0}} \mathbb{U}$ & 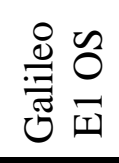 \\
\hline $90 \%$ & -26.3 & -30.3 & -32.5 & -44.6 & -38.4 \\
\hline 9 & -25.1 & -27.1 & -37.4 & -37.7 & -35.7 \\
\hline $99 \%$ & -23.5 & -24.2 & -29.5 & -29.0 & -32.3 \\
\hline $99.9 \%$ & -21.7 & -22.7 & -27.7 & -24.7 & -29.6 \\
\hline 99.9 & -20.6 & -21.1 & -25.5 & -21.3 & -26.6 \\
\hline $99.999 \%$ & -19.9 & -21.1 & -25.5 & -21.3 & -26.6 \\
\hline $99.9999 \%$ & -19.4 & -21.1 & -24.7 & -21.1 & -25.7 \\
\hline Max & -19.2 & -21.1 & -23.4 & -21.1 & -24.7 \\
\hline
\end{tabular}

\section{Cross-correlation}

In this section, we present statistics related to the values of the CAF for the cross-correlation for the GPS L1 C/A and Galileo E1 OS codes. As it will be shown, the results are relatively similar to those of the autocorrelation.

\section{GPS L1 C/A}

In presence of Doppler, the cross-correlation is similar to the autocorrelation, i.e. for an integration time of $1 \mathrm{~ms}$, the maximum crosscorrelation value can be up to $-19.1 \mathrm{~dB}$, as shown in Fig. 18. The statistics for a Doppler range of $[-10 ; 10] \mathrm{kHz}$ are provided in Table 2 . For longer integration times, a behavior similar to the one shown in Fig. 12 will be observed, and the maximum is obtained for a Doppler that is a multiple of $1 \mathrm{kHz}$.

Van Diggelen (2009, p.219) states regarding detection problem due to cross-correlations that "both the code delay and the frequency offset of the incorrect (strong) satellite would have to be in the same search zone as the intended (weak) satellite". However, this statement is not correct, because as demonstrated in the Appendix, what matters is the difference between the received and local frequencies For example, let us consider a receiver with a frequency search space of $\pm 500 \mathrm{~Hz}$, which receives two GPS L1 C/A signals, one weak with a Doppler of $300 \mathrm{~Hz}(\mathrm{PRN} 1)$ and one strong with a Doppler of $4100 \mathrm{~Hz}$ (PRN 2).
When the receiver will search PRN 1 and compute the correlation with a local Doppler of $100 \mathrm{~Hz}$, there will be a high cross-correlation with the incoming PRN 2 signal, because the difference between its frequency and the local one is $4 \mathrm{kHz}$, which is a multiple of $1 \mathrm{kHz}$.

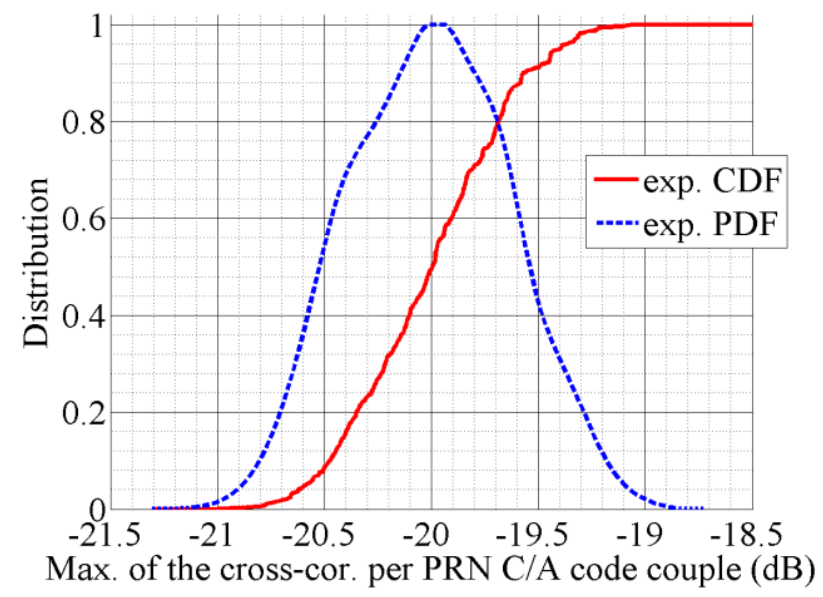

Fig. 18 Distribution of the maximum of the crosscorrelation function per GPS L1 C/A codes couple considering $[-10 ; 10] \mathrm{kHz}$ as range for the Doppler frequency

\section{Galileo E1 OS}

For Galileo E1 OS signals, two kinds of crosscorrelation should be considered. The first one deals with the correlation between the data and pilot codes assigned to the same satellite.

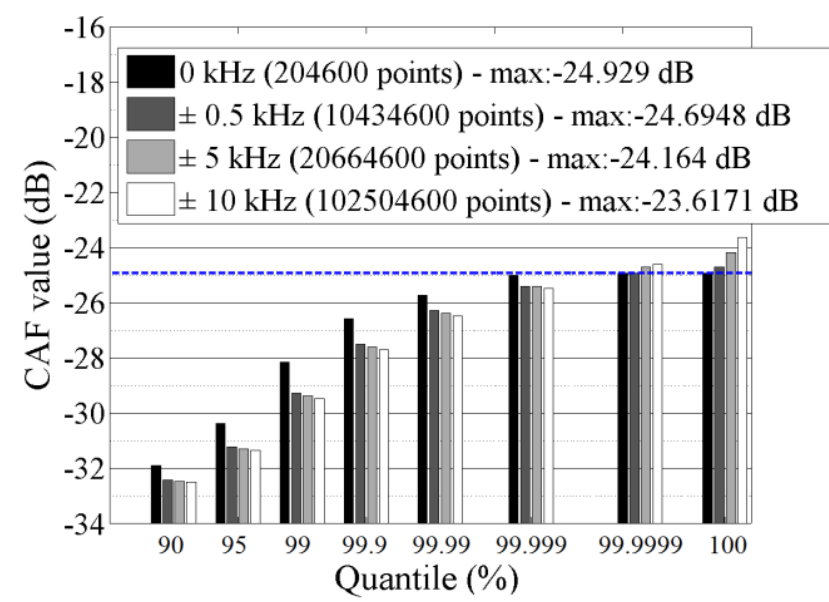

Fig. 19 Level of CAF values according to the selected quantiles and for different frequency bands, considering the 50 Galileo E1 OS code data/pilot couples of each satellite and an integration time of $4 \mathrm{~ms}$

Fig. 19 presents the statistical description of this cross-correlation. With Doppler frequency in the 
range $[-10 ; 10] \mathrm{kHz}$, the worst isolation is $-23.62 \mathrm{~dB}$.

The second Galileo cross-correlation corresponds to the correlation between 2 codes from two different satellites, Data and Data, Pilot and Pilot, Data and Pilot. Table 2 allows us to compare the maximum of each cross-correlation. The best isolation is for a code couple assigned to the same satellite. Indeed, they are chosen as orthogonal as possible to not interfere for the correlation of the local component with the received Galileo E1 OS signal.

Table 2 Levels of CAF values in $\mathrm{dB}$ according to the distribution considering $[-10 ; 10] \mathrm{kHz}$ as range for the Doppler frequency. Blank elements for Galileo E1 OS in the table were not computed due to the high number of combinations.

\section{Galileo E1 OS (4 ms)}

\section{GPS}

L1 C/A

(1 ms)

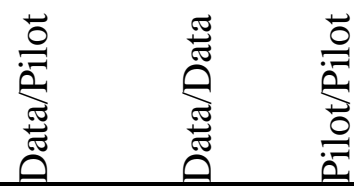

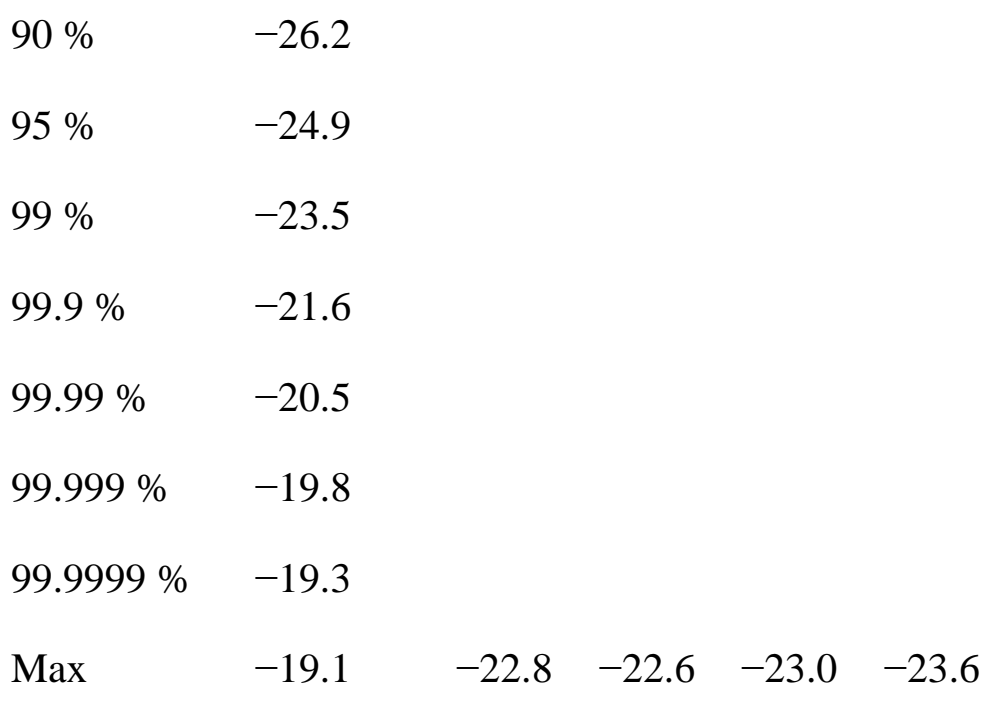

\section{Conclusion}

We have presented various results regarding the correlations of the GPS L1 C/A and Galileo E1 OS codes. Some results are relatively well-known by people working in the GNSS field but have been clarified, while some of them are less known.

In a first part, we have studied the validity of some approximations generally used. First, it was shown that the discrete summations done in GNSS receivers due to the sampling can be approximated by a continuous integration, as intuitively expected. The second point was about the classical correlator output expression, which considers the code and the Doppler frequency as independent. The region of validity of this expression has been clarified, and it is not only around the main peak as it is often thought, but also for relatively low Doppler frequencies, such as one or two hundreds of hertz with the GPS L1 C/A signal, when the theoretical code correlation is not extremely low, e.g. near $-24 \mathrm{~dB}$.

In a second part, we have provided a statistical description of the autocorrelation and crosscorrelation for GPS L1 C/A and Galileo E1 OS codes, considering different carrier frequency bands. For example, it has been shown that Galileo E1 OS codes have a lower crosscorrelation than the GPS L1 C/A codes for any Doppler frequency between -10 and $10 \mathrm{kHz}$ considering an integration time of one code period, namely $-23.44 \mathrm{~dB}$ against $-19.18 \mathrm{~dB}$. When considering all potential Doppler frequencies, comparing to no Doppler frequency the isolation is degraded by a maximum of about $2 \mathrm{~dB}$ and $4.75 \mathrm{~dB}$ for Galileo E1 OS and GPS L1 $\mathrm{C} / \mathrm{A}$ respectively. The same trends were shown for the cross-correlation. For GPS L1 C/A, the isolation is ensured to be at the minimum $19.08 \mathrm{~dB}$ for any Doppler frequency between -10 and $10 \mathrm{kHz}$, which is $2 \mathrm{~dB}$ lower than the classical value given in the literature which is only valid for frequencies that are multiple of $1 \mathrm{kHz}$. For Galileo E1 OS, the isolation between data and pilot codes affected to the same satellite is $-22.82 \mathrm{~dB}$, which is $2.34 \mathrm{~dB}$ higher than any couple of Galileo E1 OS codes. We have also highlighted the significant impact of the coherent integration time, and shown that having a coherent integration time longer than the code period provides much better correlation performance. We have also shown that even the satellites which are outside the frequency search space impact the correlation result, since what matters is the difference between the frequencies, and not the frequencies themselves.

This study could be extended in many ways. First, other GNSS signals could be considered. Then, it could be extended by considering different sampling frequencies, since the sampling 
frequency also changes the code correlation properties. Finally, in the same way, the impact of the code Doppler could be studied, especially with signals having a chipping rate of $10.23 \mathrm{MHz}$ or having pilot channels which enable long coherent integration.

\section{Acknowledgments}

The authors would like to thank Chris J. Hegarty, Jack. K. Holmes, Francis Soualle and Phillip W. Ward, for their valuable comments and advice.

\section{Appendix: Computation of the continuous-time CAF}

This appendix shows how to compute numerically the continuous-time expression given by (4). A PRN code is a succession of chips of duration $T_{c}$, whose value can be 1 or -1 , that repeats each $M$ chips; thus the duration of one code period is $T_{p}=M T_{c}$. A PRN code is illustrated in Fig. 20, and can be defined as

$c_{k}(t)=\sum_{p=-\infty}^{\infty} \sum_{m=0}^{M-1} c_{k}[m] \Pi\left(t-m T_{c}-p T\right)$

where $k$ indicates the PRN number, $c_{k}[m]$ is the PRN sequence, and $\Pi(t)=u(t)-u\left(t-T_{c}\right)$ is a boxcar function with $u(t)$ the unit step function.

Then, the product of a PRN code of $M$ chips with another PRN code of $M$ chips shifted by $\Delta_{\tau}$ chips is another code. If $\Delta_{\tau}$ is a multiple of the chip duration $T_{c}$, the resulting code is composed of $M$ chips of duration $T_{c}$, i.e. we can write

$c_{k}\left(t-n_{1} T_{C}\right) c_{l}\left(t-n_{2} T_{C}\right)=c_{k, l, \Delta_{\tau}}(t)$

$\left.m T_{c}-p T_{p}\right)$

$$
=\sum_{p=-\infty}^{\infty} \sum_{m=0}^{M-1} c_{k, l, \Delta_{\tau}}[m] \Pi(t-
$$

where $\Delta_{\tau}=\left(n_{1}-n_{2}\right) T_{c}$. If $\Delta_{\tau}$ is not a multiple of the chip duration $T_{c}$, the resulting code would be composed of $2 M$ chips, alternatively of duration $\Delta_{\tau}$ and $T_{c}-\Delta_{\tau}$.

Considering a delay that is a multiple of the chip duration, for a coherent integration over a time $T_{I}=P T_{p}$, i.e. there are $P$ code periods during the integration, the cross ambiguity function is given as

$$
\begin{aligned}
& \int_{0}^{T_{I}} c_{k, l, \Delta_{\tau}}(t) e^{j\left(2 \pi \Delta_{f} t+\varphi_{k}\right)} d t \\
& =e^{j \varphi_{k}} \int_{0}^{T_{I}} c_{k, l, \Delta_{\tau}}(t) e^{j 2 \pi \Delta_{f} t} d t
\end{aligned}
$$

$$
\begin{aligned}
&= e^{j \varphi_{k}}\left(\begin{array}{c}
\int_{0}^{T_{p}} c_{k, l, \Delta_{\tau}}(t) e^{j 2 \pi \Delta_{f} t} d t \\
+\int_{T_{p}}^{2 T_{p}} c_{k, l, \Delta_{\tau}}(t) e^{j 2 \pi \Delta_{f} t} d t \\
+\cdots \\
+\int_{(P-1) T_{p}}^{P T_{p}} c_{k, l, \Delta_{\tau}}(t) e^{j 2 \pi \Delta_{f} t} d t
\end{array}\right) \\
&=e^{j \varphi_{k}} \int_{0}^{T_{p}} c_{k, l, \Delta_{\tau}}(t) e^{j 2 \pi \Delta_{f} t} d t \\
&+\int_{0}^{T_{p}} c_{k, l, \Delta_{\tau}}\left(t-T_{p}\right) e^{j 2 \pi \Delta_{f} t} e^{-j 2 \pi \Delta_{f} T_{p}} d t+\cdots \\
&+\int_{0}^{T_{p}} c_{k, l, \Delta_{\tau}}\left(t-(P-1) T_{p}\right) e^{j 2 \pi \Delta_{f} t} e^{-j 2 \pi \Delta_{f}(P-}
\end{aligned}
$$

Since the code is periodic with a period $T_{p}$, $c_{k, l, \Delta_{\tau}}(t)=c_{k, l, \Delta_{\tau}}\left(t-T_{p}\right)=\cdots=c_{k, l, \Delta_{\tau}}(t-$ $\left.(P-1) T_{p}\right)$. Therefore,

$\int_{0}^{T_{I}} c_{k, l, \Delta_{\tau}}(t) e^{j\left(2 \pi \Delta_{f} t+\varphi_{k}\right)} d t$

$$
\begin{aligned}
& =e^{j \varphi_{k}}\left(\begin{array}{c}
\int_{0}^{T_{p}} c_{k, l, \Delta_{\tau}}(t) e^{j 2 \pi \Delta_{f} t} d t \\
+\int_{0}^{T_{p}} c_{k, l, \Delta_{\tau}}(t) e^{j 2 \pi \Delta_{f} t} e^{-j 2 \pi \Delta_{f} T_{p}} d t \\
+\cdots \\
+\int_{0}^{T_{p}} c_{k, l, \Delta_{\tau}}(t) e^{j 2 \pi \Delta_{f} t} e^{-j 2 \pi \Delta_{f}(P-1) T_{p}} d t
\end{array}\right) \\
& =e^{j \varphi_{k}}\left(\begin{array}{c}
\int_{0}^{T_{p}} c_{k, l, \Delta_{\tau}}(t) e^{j 2 \pi \Delta_{f} t} d t \\
+e^{-j 2 \pi \Delta_{f} T_{p}} \int_{0}^{T_{p}} c_{k, l, \Delta_{\tau}}(t) e^{j 2 \pi \Delta_{f} t} d t \\
+\cdots \\
+e^{-j 2 \pi \Delta_{f}(P-1) T_{p}} \int_{0}^{T_{p}} c_{k, l, \Delta_{\tau}}(t) e^{j 2 \pi \Delta_{f} t} d t
\end{array}\right) \\
& =e^{j \varphi_{k}}\left(\begin{array}{c}
1+e^{-j 2 \pi \Delta_{f} T_{p}}+\cdots \\
+e^{-j 2 \pi \Delta_{f}(P-1) T_{p}}
\end{array}\right) \int_{0}^{T_{p}} c_{k, l, \Delta_{\tau}}(t) e^{j 2 \pi \Delta_{f} t} d t \\
& =e^{j \varphi_{k}}\left(\sum_{p=0}^{P-1} e^{-j 2 \pi \Delta_{f} p T_{p}}\right) \int_{0}^{T_{p}} c_{k, l, \Delta_{\tau}}(t) e^{j 2 \pi \Delta_{f} t} d t \\
& =e^{j \varphi_{k}} \frac{1-e^{-j 2 \pi \Delta_{f} P T_{p}}}{1-e^{-j 2 \pi \Delta_{f} T_{p}}} \int_{0}^{T_{p}} c_{k, l, \Delta_{\tau}}(t) e^{j 2 \pi \Delta_{f} t} d t \\
& =e^{j \varphi_{k}} e^{-j \pi \Delta_{f}(P-1) T_{p}} \frac{\sin \left(\pi \Delta_{f} P T_{P}\right)}{\sin \left(\pi \Delta_{f} T_{P}\right)} \int_{0}^{T_{p}} c_{k, l, \Delta_{\tau}}(t) e^{j 2 \pi \Delta_{f} t} d t
\end{aligned}
$$




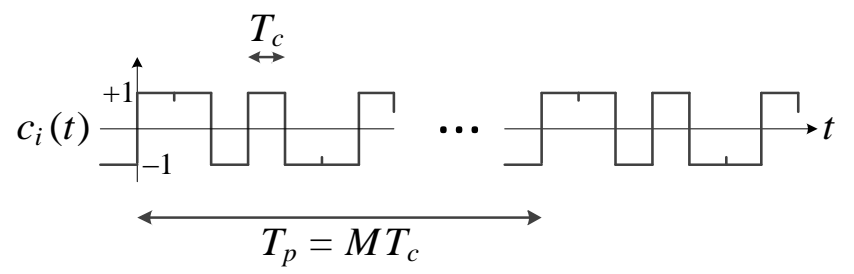

Fig. 20 Illustration of a PRN code

The remaining integral is the cross ambiguity function for a coherent integration over one code period, and is given as

$$
\begin{aligned}
& \int_{0}^{T_{p}} c_{k, l, \Delta_{\tau}}(t) e^{j 2 \pi \Delta_{f} t} d t \\
& =\int_{0}^{T_{p}} \sum_{p=-\infty}^{\infty} \sum_{m=0}^{M-1} c_{k, l, \Delta_{\tau}}[m] \Pi\left(t-m T_{c}\right. \\
& \left.-p T_{p}\right) e^{j 2 \pi \Delta_{f} t} d t \\
& =\int_{0}^{T_{p}} \sum_{m=0}^{M-1} c_{k, l, \Delta_{\tau}}[m] \Pi\left(t-m T_{c}\right) e^{j 2 \pi \Delta_{f} t} d t \\
& =\sum_{m=0}^{M-1} \int_{0}^{T_{p}} c_{k, l, \Delta_{\tau}}[m] \Pi\left(t-m T_{c}\right) e^{j 2 \pi \Delta_{f} t} d t \\
& =\sum_{m=0}^{M-1} c_{k, l, \Delta_{\tau}}[m] \int_{m T_{c}}^{(m+1) T_{c}} e^{j 2 \pi \Delta_{f} t} d t \\
& =\sum_{m=0}^{M-1} c_{k, l, \Delta_{\tau}}[m]\left[\frac{e^{j 2 \pi \Delta_{f} t}}{j 2 \pi \Delta_{f}}\right]_{m T_{c}}^{(m+1) T_{c}} \\
& =\sum_{m=0}^{M-1} c_{k, l, \Delta_{\tau}}[m] \frac{e^{j 2 \pi \Delta_{f}(m+1) T_{c}}-e^{j 2 \pi \Delta_{f} m T_{c}}}{j 2 \pi \Delta_{f}} \\
& =\sum_{m=0}^{M-1} c_{k, l, \Delta_{\tau}}[m] e^{j 2 \pi \Delta_{f} m T_{c}} \frac{e^{j 2 \pi \Delta_{f} T_{c}}-1}{j 2 \pi \Delta_{f}} \\
& =e^{j \pi \Delta_{f} T_{c}} \frac{e^{j \pi \Delta_{f} T_{c}}-e^{-j \pi \Delta_{f} T_{c}}}{j 2 \pi \Delta_{f}} \sum_{m=0}^{M-1} c_{k, l, \Delta_{\tau}}[m] e^{j 2 \pi \Delta_{f} m T_{c}} \\
& =e^{j \pi \Delta_{f} T_{c}} \frac{\sin \left(\pi \Delta_{f} T_{c}\right)}{\pi \Delta_{f}} \sum_{m=0}^{M-1} c_{k, l, \Delta_{\tau}}[m] e^{j 2 \pi \Delta_{f} m T_{c}} \\
& =T_{c} e^{j \pi \Delta_{f} T_{c}} \operatorname{sinc}\left(\pi \Delta_{f} T_{c}\right) \sum_{m=0}^{M-1} c_{k, l, \Delta_{\tau}}[m] e^{j 2 \pi \Delta_{f} m T_{c}}
\end{aligned}
$$

Therefore, the magnitude of the cross ambiguity function is

$\left|\int_{0}^{T_{I}} c_{k, l, \Delta_{\tau}}(t) e^{j\left(2 \pi \Delta_{f} t+\varphi_{k}\right)} d t\right|$

$$
\begin{aligned}
& =\left|\frac{\sin \left(\pi \Delta_{f} P T_{P}\right)}{\sin \left(\pi \Delta_{f} T_{P}\right)}\right|\left|\int_{0}^{T_{p}} c_{k, l, \Delta_{\tau}}(t) e^{j 2 \pi \Delta_{f} t} d t\right| \\
& =T_{c}\left|\frac{\sin \left(\pi \Delta_{f} P T_{P}\right)}{\sin \left(\pi \Delta_{f} T_{P}\right)}\right|\left|\operatorname{sinc}\left(\pi \Delta_{f} T_{c}\right)\right| \mid \sum_{m=0}^{M-1} c_{k, l, \Delta_{\tau}}[m] e^{j 2 \pi \Delta_{f} m}
\end{aligned}
$$

which can be computed numerically exactly. In the same way, it is possible to numerically compute the cross ambiguity function when the delay between the codes is not a multiple of one chip.

From (14) and (15), it can be seen that the magnitude of the CAF does not depend on the starting point of the integration. Therefore, performing a non-coherent integration, i.e. averaging the magnitude or the magnitude squared of consecutive CAF results, will give the same result as the magnitude of one CAF result. Consequently, the distribution of the CAF magnitude does not change with non-coherent integrations.

\section{References}

Akopian D (2005) Fast FFT based GPS satellite acquisition methods. IEE Proc - Radar Sonar Navig 152:277. doi: 10.1049/iprsn:20045096

Balaei AT, Akos D (2011) Cross Correlation Impacts and Observations in GNSS Receivers. Navig J Inst Navig 58:323 333.

Borre K, Akos DM, Bertelsen N, Rinder P, Jensen SH (2007) A Software-Defined GPS and Galileo Receiver, A Single-Frequency Approach. Birhäuser

Curran JT, Borio D, Lachapelle G, Murphy CC (2010) Reducing Front-End Bandwidth May Improve Digital GNSS Receiver Performance. IEEE Trans Signal Process 58:2399 - 2404.

Dion A, Boutillon E, Calmettes V, Liegeon E (2010) A Flexible Implementation of a Global Navigation Satellite System (GNSS) Receiver for on-board Satellite Navigation. In: Conference on Design and Architectures for Signal and Image Processing (DASIP), 2010. Edinburgh, Scotland, pp $48-53$ 
European Union (2015) European GNSS (Galileo) Open Service Signal. In Space Interface Control Document (OS SIS ICD) Issue 1.2.

Foucras M (2015) Performance Analysis of Modernized GNSS Signal Acquisition. Ph.D. thesis, Institut National Polytechnique de Toulouse

Foucras M, Julien O, Macabiau C, Ekambi B (2012) A Novel Computationally Efficient Galileo E1 OS Acquisition Method for GNSS Software Receiver. Proc. ION GNSS 2012, Institute of Navigation. Nashville, TN (USA), September, pp 365 383

Holmes JK (2007) Spread Spectrum Systems for GNSS and Wireless Communications. Artech House

Ipatov VP (2005) Spread Spectrum and CDMA: Principles and Applications. Wiley

Kaplan ED, Hegarty CJ, Ward P (2005) Understanding GPS: Principles and Applications, 2nd edn. Artech House

Leclère J (2014) Resource-efficient Parallel Acquisition Architectures for Modernized GNSS Signals. Ph.D. thesis, École Polytechnique Fédérale de Lausanne (EPFL)

Leclère J, Botteron C, Farine P-A (2013) Comparison Framework of FPGA-based GNSS Signals Acquisition Architectures. IEEE Trans Aerosp Electron Syst 49:1497 $-1518$.

Lestarquit L, Nouvel O (2012) Determining and measuring the true impact of $\mathrm{C} / \mathrm{A}$ code cross-correlation on tracking-Application to SBAS georanging. In: Position Location and Navigation Symposium (PLANS), 2012 IEEE/ION. Myrtle Beach, SC, USA, pp $1134-1140$

Margaria D, Motella B, Dovis F On the Impact of Channel Cross-Correlations in HighSensitivity Receivers for Galileo E1 OS and GPS L1C Signals, International Journal of Navigation and Observation, vol. 2012, Article ID 132078

Motella B, Lo Presti L (2010) The Math of Ambiguity: What is the acquisition ambiguity function and how is it expressed mathematically? Inside GNSS 5:20 - 28.
Navstar (2014) GPS Space Segment/Navigation User Interfaces (IS-GPS-200H).

Qaisar SU, Dempster AG (2010) Cross-correlation performance assessment of global positioning system (GPS) L1 and L2 civil codes for signal acquisition. Radar Sonar Navig IET 5:195 - 203.

Qaisar SU, Dempster AG (2007) An Analysis of L1-C/A Cross Correlation \& Acquisition Effort in Weak Signal Environments. In: Proceedings of International Global Navigation Satellite Systems Society, IGNSS Symposium. Sydney, Australia

Raghavan SH, Kumar R, Lazar S, et al (1999) The CDMA Limits of C/A Codes in GPS Applications - Analysis and Laboratory Test Results. Proc. ION GPS 1999, Institute of Navigation, Nashville, TN, USA, September, pp 569 - 580.

Soualle F (2009) Correlation and Randomness Properties of the Spreading Coding Families for the current and Fututre GNSSs. In: Fourth European Workshop on GNSS Signals and Signal Processing. Oberpfaffenhofen, Germany

Soualle F, Soellner M, Wallner S, et al (2005) Spreading Code Selection Criteria for the future GNSS Galileo. In: Proc. of the European Navigation Conf. GNSS (2005). Munich, Germany

Spilker JJ (1996) Gold Code Cross-Correlation Properties. In: GPS Signal Structure and Theoretical Performance. American Institute of Aeronautics and Astronautics

Tsui JB-Y (2005) Fundamentals of Global Positioning System Receivers: A Software Approach, 2nd edn. Wiley Series in Microwave and Optical Engineering

Van Dierendonck AJ, Erlandson RJ, McGraw GA, Coker R (2002) Determination of C/A Code Self-Interference Using CrossCorrelation Simulations and Receiver Bench Tests. Proc. ION GPS 2002, Institute of Navigation, Portland, OR, USA, September, pp 630-642

Van Diggelen FST (2009) A-GPS: Assisted GPS, GNSS, and SBAS. Artech House

Wallner S, Avila-Rodriguez J-A, Hein GW, Rushanan JJ (2007) Galileo E1 OS and GPS L1C Pseudo Random Noise Codes - 
Requirements, Generation, Optimization and Comparison -. Proc. ION GNSS 2007, Institute of Navigation, Fort Worth, TX, USA, September, pp 1549 - 1563

\section{Author Biographies}

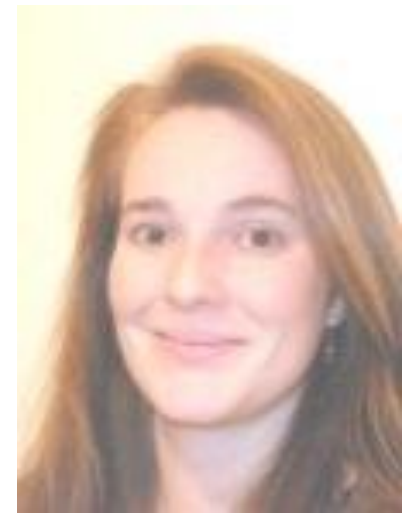

Myriam Foucras received her Masters of Sciences degree in Mathematical engineering and Fundamental Mathematics from the University of Toulouse in 2009 and 2010. She obtained her Ph.D. degree in 2015 from Ecole Nationale de l'Aviation Civile (ENAC) and funded by ABBIA GNSS Technologies, on the performance analysis of the modernized GNSS signals. In the same company, she continues her work and focuses on the performance of Galileo.

Jérôme Leclère received an engineering degree in Electronics and Signal Processing from ENSEEIHT, Toulouse, France, in 2008, and his Ph.D. in the GNSS field from EPFL, Switzerland, in 2014. He is now with the LASSENA, ÉTS, Montréal, Canada. He focuses his researches in the reduction of the complexity of the acquisition of GNSS signals, with application to hardware receivers, especially using FPGAs, and on the GNSS/INS integration.

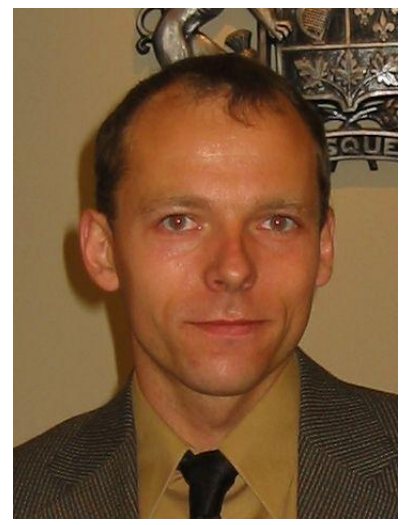

Cyril Botteron is lecturer and leading the research and project activities of the Positioning, Navigation, Timing, Sensing and Communications subgroup at EPFL. He received his $\mathrm{Ph} . \mathrm{D}$. degree in Electrical and Computer Engineering From the University of Calgary in 2003. He is the author or co-author of 5 patent families and over 100 publications in major journals and conferences in the fields of UWB-based and GNSS-based navigation and sensing, ultra-lowpower RF communications and integrated circuits design, and baseband analog and digital signal processing.

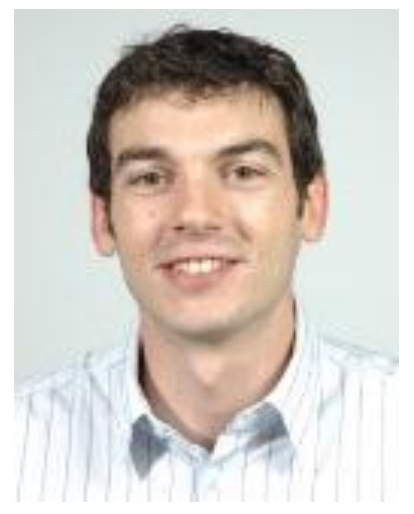

Olivier Julien is the head of the Signal Processing and Navigation (SIGNAV) research group of the TELECOM laboratory of ENAC, in Toulouse, France. His research interests are GNSS receiver design, GNSS multipath and interference mitigation and GNSS interoperability. $\mathrm{He}$ received his engineer degree in digital communications in 2001 from ENAC and his $\mathrm{PhD}$ degree in 2005 from the Departement of Geomatics Engineering 


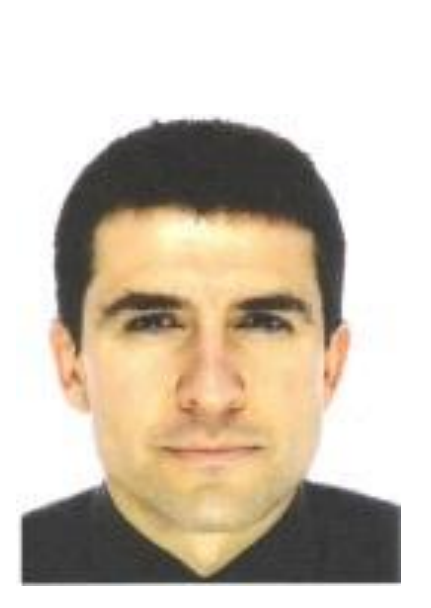

of the University of Calgary, Canada.

Christophe Macabiau graduated as an electronics engineer degree in 1992 from ENAC in Toulouse, France. Since 1994, he has been working on the application of satellite navigation techniques to civil aviation. $\mathrm{He}$ received his $\mathrm{PhD}$ degree in 1997 and has been in charge of the TELECOM laboratory of the ENAC since 2011.

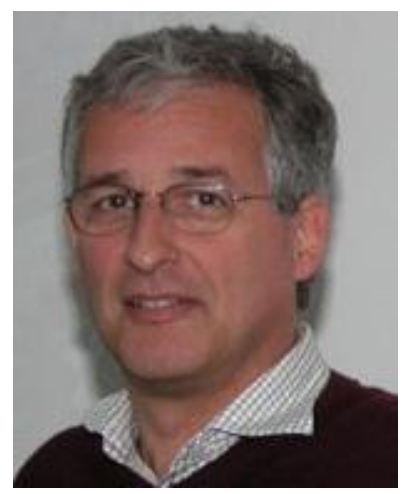

Pierre-André Farine is professor in electronics and signal processing at EPFL, and is head of the electronics and signal processing laboratory. He received the M.Sc. and Ph.D. degrees in Micro technology from the University of Neuchâtel, Switzerland, in 1978 and 1984, respectively. $\mathrm{He}$ is the author or co-author of more than 200 publications in conference and journals and more than 65 patents families.

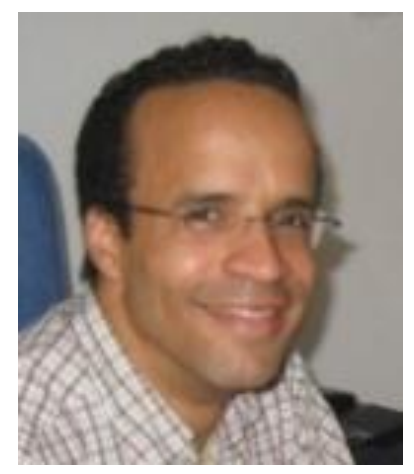

Bertrand Ekambi graduated by a Master in Mathematical

Engineering from the University of Toulouse in 1999. Since 2000, he is involved in the main European GNSS projects: EGNOS and Galileo. $\mathrm{He}$ is the founder manager of ABBIA GNSS Technologies, a French SME working on Space Industry, based in Toulouse, France. 